FEDERAL RESERVE BANK OF SAN FRANCISCO

WORKING PAPER SERIES

\title{
A Rising Natural Rate of Unemployment: Transitory or Permanent?
}

\author{
Mary Daly \\ Federal Reserve Bank of San Francisco \\ Bart Hobijn \\ Federal Reserve Bank of San Francisco \\ Aysegul Sahin, \\ Federal Reserve Bank of New York \\ Rob Valletta \\ Federal Reserve Bank of San Francisco \\ September 2011 \\ Working Paper 2011-05
}

http://www.frbsf.org/publications/economics/papers/2011/wp11-05bk.pdf

The views in this paper are solely the responsibility of the authors and should not be interpreted as reflecting the views of the Federal Reserve Bank of San Francisco or the Board of Governors of the Federal Reserve System. 


\title{
A Rising Natural Rate of Unemployment: Transitory or Permanent?
}

\author{
MARY DALY*, BART HoBIJn, AyŞEGÜl ŞAHIN, AND RoBERT VALLETTA
}

September 9, 2011

\begin{abstract}
The U.S. unemployment rate has remained stubbornly high since the 2007-2009 recession leading many to conclude that structural, rather than cyclical, factors are to blame. Relying on a standard job search and matching framework and empirical evidence from a wide array of labor market indicators, we examine whether the natural rate of unemployment has increased since the recession began, and if so, whether the underlying causes are transitory or persistent. Our analyses suggest that the natural rate has risen over the past several years, with our preferred estimate implying an increase from its pre-recession level of close to a percentage point. An assessment of the underlying factors responsible for this increase, including labor market mismatch, extended unemployment benefits, and uncertainty about overall economic conditions, implies that only a small fraction of this increase is likely to be persistent.
\end{abstract}

Keywords: equilibrium unemployment, Beveridge curve, structural unemployment, mismatch JEL codes: E24, J3, J6.

*Corresponding author (email: mary.daly@sf.frb.org). Daly, Hobijn, and Valletta are at the Federal Reserve Bank of San Francisco; Şahin is with the Federal Reserve Bank of New York. The authors are grateful to Glenn Rudebusch and John Williams for their suggestions and comments. The views expressed in this paper are solely those of the authors and are not attributable to the Federal Reserve Banks of New York and San Francisco or the Federal Reserve System. This version covers data through August 20 $0^{\text {th }}, 2011$. 


\section{Introduction}

The recent financial crisis and ensuing deep recession led to a sharp increase in the U.S. unemployment rate, which peaked at 10.1 percent in October 2009. After adjusting for changes in the demographic composition of the labor force, this represents the highest unemployment rate reached since the Great Depression. ${ }^{1}$ Moreover, in contrast to relatively rapid labor market recoveries following prior deep postwar recessions, the unemployment rate has edged down very slowly since the recession, remaining above 9 percent more than two years into the recovery. As such, the typical duration of an unemployment spell is well above the highs observed in past downturns.

Persistently anemic labor market conditions are partly a reflection of the sluggish overall economic recovery, which is a common occurrence following financial crises (Reinhart and Rogoff, 2009). The resulting lackluster pace of job creation has barely kept up with trend labor force growth and therefore has not generated enough jobs to make a significant dent in the unemployment rate or reduce unemployment duration. Moreover, the unemployment rate has remained high relative to its historical relationship with other cyclical indicators. For example, it exceeds the level implied by the Beveridge curve, which relates it to the strength of labor demand as reflected in the number of vacancies posted.

This disconnect between the unemployment rate and other aggregate indicators has raised the concern that rather than being purely cyclical, the recent elevated level of unemployment contains a substantial structural component. Since most short-run monetary and fiscal stabilization polices are designed to address cyclical, rather than structural issues, understanding the relative contributions of each to total unemployment is an important policy goal. ${ }^{2}$ Unfortunately, it is also a

\footnotetext{
${ }^{1}$ Due to changes in the demographic composition of the labor force, the aggregate unemployment rate in the recent recession did not reach the peak from the 1981 recession (see Elsby, Hobijn, and Şahin, 2010)

2 For example, accommodative monetary policy can reduce cyclical unemployment but cannot directly affect structural unemployment associated with skill or geographic mismatch, changes in benefit systems, or changes in search frictions.
} 
challenging task, a point made by Peter Diamond (2011) in his Nobel Prize Lecture ${ }^{3}$ and illustrated by the wide span of views held by both economists and policymakers.

In this paper, we assess the degree to which the natural rate of unemployment has changed and the reasons underlying such a change. We do so in two parts.

In the first part, we discuss the implications of a standard textbook model of frictional unemployment based on a search and matching framework (Pissarides 2000, Chapter 1). In this model, equilibrium unemployment is determined by the intersection of two curves: the Beveridge curve, which reflects the steady-state relationship between vacancies and the unemployment rate; and the Job Creation curve, which reflects employers' decisions to create job openings and can be loosely interpreted as an aggregate labor demand curve. Our empirical estimates of these curves in the short and long term reveal recent movements that are similar to those that occurred in previous severe recessions. Putting these two curves together, we estimate that the equilibrium or natural rate of unemployment has increased over the recession and recovery, but by far less than unemployment has risen. Our preferred estimate points to an increase in the natural rate of unemployment over the cycle of about one percentage point putting the current natural rate at around 6 percent. Importantly, even at the maximum of our range of plausible estimates, we find the natural rate increased by no more than one and half percentage points, boosting the current natural rate to about 6 and one half percent. ${ }^{4}$ We also discuss the implications of the higher natural rate for broader measures of economic activity, specifically the output gap, based on Okun's Law.

In the second part of the analysis, we focus on the three primary factors that economists have offered that may account for an increase in the natural rate: (1) a mismatch between the characteristics of job openings, such as skill requirements or location, and the characteristics of the unemployed; (2) the availability of extended unemployment insurance (UI) benefits, which may reduce the intensity of job search or prolong labor force attachment for UI recipients; and (3) uncertainty about overall economic conditions, which may have induced firms to raise

\footnotetext{
${ }^{3}$ In arguing against claims that the much of the increase in unemployment was structural, Diamond stated: I am skeptical of the value of attempting to separate cyclical from structural unemployment over a business cycle"

${ }^{4}$ For context, the maximum natural rate recorded by the Congressional Budget Office (CBO) was 6.3 percent in 1978.
} 
productivity and output without extensive hiring of new employees. ${ }^{5,6}$ Because the mismatch argument has multiple components, we discuss an array of evidence, which on balance suggests that the increase in mismatch has been quite limited and largely reflects transitional factors. We find a larger contribution arising from extended UI benefits, which are planned to expire as the labor market recovers and therefore constitute a transitory influence on the natural rate. Finally, we provide speculative evidence that the unusual degree of uncertainty may be contributing to elevated unemployment through the resulting suppression of hiring; like extended UI, the influence of this factor is likely to be transitory as well.

Taking these two parts together, we conclude that although the natural rate of unemployment has risen over the last few years, substantial slack remains in the labor market, and is likely to persist for several years. Moreover, since most of the increase in the natural rate appears to be transitory, we expect that as the cyclical recovery in the labor market proceeds, the natural rate will fall back to a value close to its pre-recession level of around 5.0 percent.

\section{Equilibrium unemployment and the natural rate}

The increase in the U.S. unemployment rate associated with the 2007-2009 recession is unprecedented during the postwar era. The unemployment rate rose by 5.7 percentage points from a low of 4.4 percent in late 2006 and early 2007 to 10.1 percent in October 2009; this exceeds the net increase of 5.2 percentage points between mid-1979 and late 1982 (which spans two recessionary episodes). Moreover, two years into the recovery (as of the third quarter of 2011), the unemployment rate has declined by only about 1 percentage point.

This pattern of persistently elevated unemployment raises the possibility that in addition to the usual cyclical increase, an elevated structural component and corresponding higher natural rate may be may be contributing as well. As defined in Brauer (2007), the natural rate of unemployment "arises from all sources other than fluctuations in demand associated with business cycles. The natural rate is determined by the rate at which jobs are simultaneously created and destroyed, the

\footnotetext{
${ }^{5}$ Basu, Fernald, Kimball (2006) find that positive productivity shocks can reduce employment.

6 This evidence draws upon our previous work on the labor market during the recession and recovery: Daly and Hobijn (2010), Elsby, Hobijn, and Şahin (2010), Kwok, Daly, and Hobijn (2010), Valletta and Kuang (2010a,b), as well as Wilson (2010).
} 
rate of turnover in particular jobs, and how quickly unemployed workers are matched with vacant positions. Those factors in turn depend on the characteristics of jobs and of workers and on the efficiency of the labor market's matching process." Given the severe shock to labor markets, it is reasonable to ask whether some of these noncyclical factors have been altered in a way that increases the natural rate of unemployment in either the short or the long term.

\subsection{Frictional unemployment in equilibrium}

To assess the factors affecting the unemployment rate in the short run as well as its longer run level, we rely on the model of equilibrium frictional unemployment from Pissarides (2000, Chapter 1). This model specifies two curves that determine equilibrium frictional unemployment: the Beveridge Curve (BC) and the Job Creation curve (JCC). We use this framework to analyze the potential increase in the natural rate of unemployment, focusing here on a nontechnical discussion of the model's key elements. ${ }^{7}$

In models of unemployment due to search frictions, not every employer that is looking to hire finds a worker and not every job searcher finds an employer. Therefore, the labor market does not fully clear in each period, and some job openings remain unfilled at the same time that some job seekers remain unemployed. ${ }^{8}$ Wage determination is ancillary to the job matching process in these models. Because employers and job seekers each benefit from a job match, wages are determined by the bargain between employers and employees over the surplus generated by the match, which occurs after the match and therefore is irrelevant to its formation. ${ }^{9}$ As such, the equilibrium in this model is defined in terms of vacancies and unemployment - the intersection of the BC and JCCrather than wages and the equilibrium level of employment.

Figure 1 depicts typical BC and JCC curves and illustrates the interactions between them that produce equilibrium vacancy and unemployment rates (based on Figure 1.2 in Pissarides 2000, p. 20). The BC starts with a job matching function, which specifies that the rate at which job seekers are matched to job openings depends primarily on the ratio of the job vacancy rate to the

7 See Daly, Hobijn, and Valletta (2011) for further details regarding the underlying model.

${ }^{8}$ By contrast, in frictionless models of the labor market, wages adjust to equate labor demand to labor supply in a spot market, which excludes the existence of unemployment as an equilibrium outcome.

9 Assumptions about the type of wage bargaining are important for the cyclical properties of the model (Pissarides, 2009) but are not important for the equilibrium concept we focus on here. 
unemployment rate (Petrongolo and Pissarides, 2001). In conjunction with standard conditions that determine unemployment as the outcome of job separations and hiring (e.g., Shimer 2005), job matching functions imply a negative relationship between the unemployment rate and the job vacancy rate. When labor demand is strong, vacancy rates are high and the unemployment rate is low; the reverse is true when labor demand is weak. ${ }^{10}$ The position of the BC can also change, with outward shifts occurring when the pace of layoffs rises or the efficiency of the job matching process declines.

By itself, the BC does not determine an equilibrium combination of vacancies and unemployment because it does not incorporate other key determinants of overall labor demand. The missing relationship is the JCC, which in its simplest form is determined by a free entry condition. Assuming no constraints on vacancy postings, firms will create vacancies up to the point where the expected value of a job match equals the expected search cost to fill the vacancy; the latter combines direct recruiting costs for firms with the probability that the job is filled.

The relevant literature on frictional unemployment has not attempted to pin down the quantitative determinants of the JCC, focusing instead on the shape of the BC and the types of frictions that underlie it. However, in the simple model we discuss here, the JCC is upward sloping, implying that firms have incentives to create more job openings when unemployment is higher (as depicted in Figure 1). ${ }^{11}$ In our specific setting, the upward slope arises because as the pool of job seekers grows, employers can more easily fill open vacancies; the resulting increase in the probability that a vacancy is filled and the associated reduction in net hiring costs raises vacancy creation by firms. The exact degree of upward slope is affected by other factors that may change over time or across the business cycle, such as the efficiency of the matching process, the job separation rate, the level of recruiting costs, and the value of jobs (as reflected in worker productivity and the value of output). ${ }^{12}$

\footnotetext{
${ }^{10}$ The concave shape of the $\mathrm{BC}$ in this figure reflects a matching technology with constant returns to scalei.e., a doubling of job vacancies and unemployed individuals implies a doubling of job matches - hence diminishing returns to either of these inputs by itself. This assumption has ample empirical support (Petrongolo and Pissarides 2001).

${ }^{11}$ The same is true of some models with matching functions based on more elaborate micro-foundations (e.g., Shimer 2007)

${ }^{12}$ More generally, it depends on the structure of the product and labor markets in which firms operate and how they bargain over wages, as well as external factors such as the discount or interest rate.
} 
The key implication of this model for our analysis is that the equilibrium unemployment rate is determined jointly by the BC and JCC equations. ${ }^{13}$ Figure 1 illustrates equilibrium in our simple model of frictional unemployment. For a given BC and JCC, the equilibrium unemployment rate at point $a$ is determined by the intersection of the two curves. In this framework, changes in the equilibrium unemployment rate can occur due to an outward shift in the BC, a downward shift in the JCC, or a combination of both.

We first consider an outward shift in the BC, from BC to BC', shown in Figure 1. For a given JCC, this shifts the equilibrium from $a$ to $b$. Because the JCC is upward sloping, equilibrium unemployment increases by less than the outward shift in the $\mathrm{BC}$, to a degree that depends on the slope of the JCC. In order for the unemployment rate to increase by the same amount as the rightward shift in the $\mathrm{BC}$, the JCC either must be flat or must shift outward (or down) as well. This is illustrated by the shift in $\mathrm{JC}$ to $\mathrm{JC}^{\prime}$ in Figure 1. This results in a shift in equilibrium from $b$ to $c$.

This simple graphical analysis provides us with two key insights. First, to understand the driving forces of the rise in the unemployment rate, one must consider not only what is shifting the $\mathrm{BC}$ and by how much, but also what is affecting job creation, i.e. labor demand. Second, to distinguish what part of the rise in the unemployment rate reflects purely cyclical fluctuations in labor demand and what parts are due to other factors, either transitory or permanent, that cause a rise in the natural rate, one has to consider what is driving the shifts in the $\mathrm{BC}$ and the JC curves and how long these effects are likely to last.

\subsection{The recent shift in the Beveridge Curve}

Figure 2 shows the empirical U.S. BC based on the monthly vacancy data from the Job Openings and Labor Turnover Survey (JOLTS), available beginning in December 2000. The data are divided into two groups, with the observations occurring prior to the recent recession in blue and the observations occurring since the start of the recession in orange. The last data point in our sample is June 2011. In addition to the observed data, the figure contains a fitted BC, which is an update of the estimate provided in Barnichon, Elsby, Hobijn, and Şahin (2010). In terms of our

\footnotetext{
${ }^{13}$ This is an important point that is frequently overlooked in policy discussions related to movements in the $\mathrm{BC}$ in which shifts in the $\mathrm{BC}$ are interpreted as one-for- one increases in the natural rate of unemployment.
} 
simple framework the fitted curve can be interpreted as an empirical estimate of the $\mathrm{BC}$ depicted in Figure 1 based on the pre-recession patterns of job matching.

In June 2011 the actual unemployment rate was 9.2 percent while the level of the unemployment rate on the fitted $\mathrm{BC}$ at the observed 2.3 percent vacancy rate is 6.6 percent. This implies the 2.6 percentage point unemployment gap, or implied outward BC shift, that is plotted in the figure. ${ }^{14}$ It is important to note that the size of the implied shift has varied substantially and at high frequency over the past few years. For example, during the few months between late 2010 and early 2011, the implied shift fell from over 3 percentage points to about 2.0 percentage points. This variation in the implied shift occurs because the recently observed points are near a very flat part of the $\mathrm{BC}$, which combines large changes in the unemployment rate with small changes in vacancy rates. Such short-run variability in the size of the gap suggests that little weight should be placed on its individual monthly values.

Moreover, while the current estimate of a 2.6 percentage-point horizontal shift in the $\mathrm{BC}$ seems large, it is important to put this estimate into a longer-term historical perspective than that enabled by the JOLTS data. Construction of a historical BC before 2000 involves merging data from JOLTS with the Help-Wanted Index published by the Conference Board. We use such a series as constructed by Barnichon (2010). Figure 3 displays the resulting long-term BC. As can be seen from the figure, the BC shifted rightward about 4 percentage points between the 1960s and the early 1980s and then shifted back about 2.5 percentage points between 1984 and 1989. This suggests that the current outward shift of the $\mathrm{BC}$ is within the range of shifts that occurred during past business cycles. Moreover, the outward shifts in previous recessions have coincided with increases in the natural rate of unemployment that are much smaller than the horizontal movement in the $\mathrm{BC}$. This is not only true for the $\mathrm{CBO}$ estimate of the natural rate but also for the most commonly used alternative estimates (Orphanides and Williams, 2002). Credible estimates of the natural rate over these earlier periods suggest that it may have changed about half as much as the horizontal shift in the empirical BC.

An alternative way to consider the current shift in the $\mathrm{BC}$ is presented in Barnichon, Elsby, Hobijn, and Şahin (2010). They observe that currently, the job-finding rate is well below its level

\footnotetext{
${ }^{14}$ The size of the imputed current gap is not very sensitive to the estimation method applied. The non-linear OLS estimate in Valletta and Kuang (2010b) yields a similar size gap, as does the recalibrated version of Shimer's (2007) BC model presented by Kocherlakota (2010).
} 
implied by the estimated matching function based on pre-recession data. This suggests a substantial decline in match efficiency. They proceed by constructing the shifted empirical BC displayed in Figure 2, which takes into account the estimated percentage decline in match efficiency. From the shifted $\mathrm{BC}$ in the figure it can be seen that, due to the non-linear nature of the $\mathrm{BC}$, the horizontal shift is not uniform. At the 2.3 percent vacancy rate in June 2011 the estimated horizontal shift is 1.8 percentage points. At the 3.0 percent vacancy rate consistent with a pre-recession natural rate of unemployment equal to 5 percent, the horizontal shift is 1.4 percentage points.

Hence, our analysis of the shift in the BC highlights several difficulties with relying on simple plots of the BC to make inferences about changes in equilibrium unemployment. First, our estimates of the shift in a non-linear BC suggest that the horizontal shift is not uniform but instead is larger at lower levels of the vacancy rate. Second, and most importantly, past horizontal shifts in the $\mathrm{BC}$ have coincided with much smaller movements in the natural rate of unemployment. This underscores the empirical relevance of the other curve in the model — the JCC.

\subsection{An estimate of the long-run JCC}

Our analyses suggest that, at an average pre-recession vacancy rate of 3 percent, the BC has shifted outwards by 1.4 percentage points. It is tempting to infer from this that the natural rate of unemployment has thus increased from its pre-recession level of 5 percent to 6.4 percent now. However, as discussed in conjunction with Figure 1 earlier, this is equivalent to the claim that the JCC has shifted out by a corresponding amount or is flat, which is unlikely. The 6.4 percent value is more appropriately interpreted as an upper bound on the current natural rate. The actual change, i.e. the shift from $a$ to $b$ in Figure 1, depends on the shape of the JCC, in particular its upward slope.

To our knowledge, there are no existing estimates of the historical U.S. JCC. We therefore provide a rudimentary estimate here, based on the observation noted from Figure 3 that, historically, outward shifts of the BC have coincided with increases in the CBO's estimate of the natural rate of unemployment. These historical data also show that when the BC shifts outwards, the average vacancy rate generally increases. The average vacancy rate at a particular value of the natural rate of unemployment can be interpreted as an estimate of the natural vacancy rate. Hence, Figure 3 suggests that the natural rate of vacancies is increasing in the natural rate of unemployment. 
We analyze this observation more formally based on Figure 4, which plots the historical vacancy rate series used earlier against the CBO's estimate of the natural rate of unemployment. The vertical lines created by sub-sets of the points in the figure depict cyclical fluctuations in labor demand for a given level of the natural rate. Each of these lines coincides with a different location of the $\mathrm{BC}$ in Figure 3.

A regression of the historical vacancy rate series on the natural rate of unemployment, using data points observed prior to the recent recession, yields the statistically significant upward sloping relationship depicted by the dashed line in Figure 4. This regression line can be interpreted as an estimate of the long-run JCC; it reflects typical vacancy creation, i.e. labor demand, as a function of the natural rate of unemployment.

The estimated JCC slope of 1.1 in Figure 4 probably is at the high end of the range of plausible estimates. The reason is that there is neither agreement on the right historical measure of the U.S. vacancy rate, i.e. the dependent variable in the regression, nor on the estimates of the natural rate of unemployment, the explanatory variable in the regression. Abraham (1987) pointed out that some of the variation in the Help-Wanted Index data used for the construction of the historical vacancy rate time series reflect a longer-run trend due to the occupational mix of job openings, the consolidation in the newspaper industry, and the increased requirements to post job openings for Equal Employment Opportunity purposes. These factors likely drove up the index relative to the actual number of vacancies during the period of rising unemployment in the 1970s and 1980s. This might lead to an overestimate of the slope of the long-run JCC. ${ }^{15}$

Other estimates of the natural rate of unemployment, including those computed by Orphanides and Williams (2002) that allow for more time variation in the natural rate, would produce different estimates of the slope of the JCC as well. In these cases the estimated regression line in Figure 4 would be flatter, i.e., the responsiveness of the average level of vacancies to the natural rate of unemployment would be weaker. That said, the empirical JCC would remain upward sloping.

\footnotetext{
${ }^{15}$ Unreported results based on a vacancy rate measure that corrects for these issues still yield a significantly upward sloping long-run JCC.
} 


\subsection{Putting the BC and JC curves together}

To assign some magnitude to the potential increase in the natural rate of unemployment we combine the fitted and shifted JOLTS-based BC discussed above with the estimated long-run JCC curve from Figure 4. As can be seen from Figure 5, the shifted BC and the empirical JCC curve intersect at an unemployment rate of 5.4 percent. ${ }^{16}$ Note that this is substantially lower than the 6.4 percent upper bound on the natural rate of unemployment that we obtained by simply considering the horizontal shift in the BC.

Given the simplicity of our estimation strategy for the JCC, the estimated natural rate of 5.4 percent reflects considerable uncertainty. If one were to use alternative time varying estimates of the NAIRU to estimate the empirical JCC, it would flatten out and the estimate of the natural rate would increase. For this reason, we interpret the 5.4 percent estimate as a lower bound on the current natural rate of unemployment.

Thus, we find that if the currently estimated shift in the $\mathrm{BC}$ is permanent and the economy returns to its long-run JCC, then the long-run natural rate of unemployment has increased from its 5 percent level in 2007 to somewhere between 5.4 and 6.4 percent as of June $2011 .{ }^{17}$ In the absence of additional evidence to pin down its exact value, we regard 5.9 percent, the midpoint of this range, as our preferred estimate of the current long-run natural rate of unemployment.According to our estimate of the shifted $\mathrm{BC}$, this 5.9 percent natural rate of unemployment corresponds to a new natural vacancy rate of 3.3 percent. This is substantially higher than the 3.0 percent natural vacancy rate associated with the pre-recession natural rate of unemployment and fitted Beveridge Curve.

\subsection{Implications for potential GDP}

In June 2011, the unemployment rate was 9.2 percent, 3.3 percentage points above our estimate of the new natural rate, while the vacancy rate was 2.3 percent, a percentage point lower

\footnotetext{
${ }^{16}$ In Figure 5, the empirical JCC intersects the fitted pre-recession Beveridge curve at a 5 percent unemployment rate, which is the $\mathrm{CBO}$ estimate of the pre-recession level of the natural rate.

${ }^{17}$ It is useful to note that as the recovery has proceeded our estimated range for the natural rate has been falling. For example, in January 2011 we estimated the range to be bounded at 6.9 percent rather than the 6.4 percent we find currently. We interpret this decline as partially reflecting data revisions to JOLTS and partially reflecting the evolution of unemployment and vacancies in 2011. The latter of these two points to the rising importance of weak aggregate demand in determining the elevated unemployment rate.
} 
than the new natural vacancy rate. This 3.3 percentage point unemployment gap, by definition, then reflects a shortfall in the demand for labor associated with this business cycle.

To map this shortfall in labor demand into a broader measure of the shortfall in overall economic activity relative to its full employment level, one has to consider how the unemployment gap is related to the output gap. The output gap is the percentage difference between actual GDP and potential GDP. The historically relatively stable statistical relationship between these two gaps is known as Okun's Law. ${ }^{18}$

Figure 6 shows Okun's Law based on the output and unemployment gaps implied by the CBO's (2011) historical estimates of potential GDP and the natural rate of unemployment. As can be seen from the figure, a reasonable rule of thumb is that for every percentage point that the unemployment rate exceeds its natural rate GDP drops two percentage points below its potential.

During the recession and in 2009 and 2010, we saw historically large deviations from Okun's Law with the unemployment rate being more than a percentage point higher than implied by the shortfall in output relative to potential. This was mainly due to high average labor productivity growth during that period (Daly and Hobijn, 2010) and added to the concerns that the natural rate of unemployment had increased and that the actual unemployment gap was smaller than implied by the CBO estimate. However, the decline in the unemployment rate in the first quarter of 2011 combined with revised and slowerGDP growth, has brought the unemployment and output gaps back in line with the historical Okun's Law relationship.

Our analysis here suggests that the natural rate of unemployment is likely to be about 0.9 percentage points higher than the CBO estimate used in Figure 6. In that case, the unemployment gap would be 0.9 percentage points lower as well and, to be in line with Okun's Law, potential GDP would be about 1.8 percent less than the current CBO estimate, which amounts to $\$ 290$ billion (annualized). The corrected output gap in 2011Q2 would be 5.0 percent rather than 6.8 percent.

In the context of the IS-LM/AS-AD framework that is often used in textbooks on macroeconomics, ${ }^{19}$ this implies that the shortfall of actual GDP relative to its full employment level, often referred to as economic slack, is less than based on the CBO estimates. This means that there is less room for short-run fiscal and monetary policies to stimulate aggregate demand without

\footnotetext{
${ }^{18}$ After Arthur Okun, who first documented it in Okun (1962).

${ }^{19}$ See Abel, Bernanke, and Croushore (2011, Chapter 9) for example.
} 
putting upward pressures on inflation. However, even if the output gap since the beginning of the recession was 1.8 percent lower than currently estimated it would still be the second highest, after that of the early 1980's, during the postwar period.

\section{What is shifting the Beveridge and Job Creation curves?}

Our estimate of a 0.9 increase in the natural rate of unemployment based on the shifted $\mathrm{BC}$ and long-run JCC in the previous section depends on two important assumptions. The first is that the labor market will return to its long-run JCC and that there are no factors that will permanently reduce job creation. The second is the assumption that the entire estimated shift of the $\mathrm{BC}$ is permanent rather than attributable, at least in part, to temporary factors whose influence is likely to fade in the future. This raises the question of what factors affect the current positions of the $\mathrm{BC}$ and JCC curves and whether these factors reflect permanent or transitory influences. We discuss the factors, beyond weak aggregate demand and layoffs, which are most commonly considered as moving the $\mathrm{BC}$ and $\mathrm{JCC}$ in this section.

Table 1 lists the five factors we consider, how they affect the BC and the JCC, and whether they are likely to be transitory or persistent. The factors are divided into two groups: normal cyclical shifters, and other factors. Our main focus in this section is on the latter. While we do not provide a detailed discussion of the shortfall in aggregate demand or the elevated level of layoffs, we do spend some time discussing how the unusual level of uncertainty in the current environment may be affecting firm hiring and relate that back to both cyclical and structural unemployment.

As for weak aggregate demand, we consider this to be the determinant of the unemployment fluctuations beyond those captured by the natural rate. That is, it drives the shortfall in labor demand that depresses job creation and, for a given Beveridge curve, generates the cyclical move along the Beveridge curve.

The omission of layoffs relates to the fact that elevated layoffs rates tend to play an important role during the onset of recessions but they are of much less importance during recoveries. ${ }^{20}$ Bowden (1980), Blanchard and Diamond (1989), and Mortensen (1994) all emphasize

\footnotetext{
${ }^{20}$ This has been documented for the U.S. by, among others, Darby, Haltiwanger, and Plant $(1985,1986)$ and Fujita and Ramey (2009). Elsby, Hobijn, and Şahin (2008) show that this is also true across countries.
} 
that counter-clockwise loops in $(\mathrm{u}, \mathrm{v})$-space are commonly observed during U.S. business cycles and consistent with the simple theoretical framework we consider. Such loops are partly driven by an initial outward shift in the Beveridge curve driven by layoffs and a subsequent return inward during the recovery when layoffs dissipate, vacancies get posted, and the unemployment rate declines. These loops are evident in Figure 3. However, since measured layoff rates from the JOLTS data have returned to their pre-recession levels, we do not consider them a concern for the labor market recovery going forward and therefore do not address them below.

In the remainder of this section we provide recent empirical evidence on the potential importance of each of these three other factors in Table 1 and discuss whether these factors are likely to be transitory or permanent.

\subsection{Mismatch}

The mismatch argument for sustained increases in the unemployment rate and the natural rate of unemployment is predicated on imbalances in labor supply and demand across industry sectors, geographic areas, or skill groups. There is always a certain degree of mismatch in the labor market which explains why matches do not take place instantaneously. Any rise in mismatch above its usual level however makes it harder than usual for workers to find a job and more expensive for firms to fill a vacancy. The result is a decline in match efficiency that both shifts the $\mathrm{BC}$ out and the JCC down. Mismatch is generally regarded as the main potential cause of a long-run increase in the natural rate since training or relocating workers and jobs take a substantial amount of time.

A highly uneven distribution of job gains and losses across industry sectors and states is an indication of mismatch in the sense that it suggests that those who become unemployed did not work in industries and regions where hiring is taking place. Valletta and Kuang (2010b) show that the dispersion of employment gains and losses across industries and states spiked in the most recent recession. However, as aggregate employment stabilized, the dispersion of employment gains and losses across industries and states returned to its pre-recession level.

Even though the dispersion of employment gains and losses across industries and states declined substantially, there is still a large number of unemployed workers who previously held jobs in sectors like construction and financial activities. Since it is likely to take a long time for these 
sectors to return to their pre-recession employment levels, these workers might suffer from prolonged spells of unemployment due to skill mismatch.

To address this concern, Şahin, Song, Topa, and Violante (2011) introduce mismatch indices that combine measures of both labor demand and labor supply. For the former they use vacancy data from the JOLTS and the Help Wanted OnLine (HWOL) while for the latter they rely on unemployment measures from the Current Population Survey (CPS). These indices show that both sectoral as well as occupational mismatch increased during the recession but that geographic mismatch across states is relatively small. At the sectoral level, this increase can be traced back to construction, durable goods manufacturing, health, and education sectors. Occupational mismatch rose mostly due to the behavior of construction, production work, health care, and sales-related occupations.

Şahin, Song, Topa, and Violante (2011) also quantify how much of the recent rise in U.S. unemployment is due to an increase in mismatch and find that higher mismatch across industries and occupations accounts for 0.8 to 1.4 percentage points of the recent rise in the unemployment rate. Geographical mismatch turns out to be quantitatively insignificant. ${ }^{21}$

However, these findings do not necessarily imply that natural rate of unemployment increased by the same amount. Just like the dispersion measures considered in Valletta and Kuang (2010b) the mismatch indices constructed by Şahin, Song, Topa, and Violante (2011) rose during the recession and then started to decline in 2010. Thus far, the evidence suggests that mismatch has had a pronounced cyclical component, moving together with the unemployment rate. While mismatch has contributed to the increase in the unemployment rate, its current path suggests that it is not likely to cause a large long-lasting increase in the natural rate of unemployment.

Consistent with this, we expect a modest increase in the natural rate due to the contraction of the construction sector. A simple back-of-the-envelope calculation also supports our view. The seasonally adjusted unemployment rate for construction workers has been hovering around 20 percent in recent months, compared with a more typical rate from 2003 to 2006 of about 7 to 8

${ }^{21}$ This result for geographic mismatch is consistent with recent empirical papers, most notably Molloy, Smith, and Wozniak (2010) and Schulhofer-Wohl (2010), and Valletta (2010) which all find a very limited role for geographic immobility of unemployed individuals whose home values have fallen below the amount owed on their mortgages ("house lock"). Recent theoretical work by Sterk (2010) suggests that although house lock will lead to an outward shift in the BC, the likely shift is much smaller than the one depicted in Figure 2. 
percent. This represents about 1.25 million more unemployed construction workers in the current recovery than was typical during the preceding expansion. Assuming that half of them are reemployable, ${ }^{22}$ structural unemployment would increase by only about 0.4 percentage point.

Because most construction workers are not hired through formal job openings we expect the effect of this type of mismatch on the long-run JCC curve to be limited. Instead, we think that this effect of mismatch on the natural rate of unemployment is mainly due to the persistent part of the contribution of the contruction sector to the outward shift of the Beveridge curve calculated by Barnichon, Elsby, Hobijn, and Şahin (2010).

\subsection{Extended unemployment benefits}

Another potentially important factor that may be influencing the search behavior of unemployed workers and boosting the underlying structural unemployment rate is the extended availability of unemployment insurance (UI) benefits. UI extensions are a standard policy response to elevated cyclical unemployment, and the sharp increase in the unemployment rate during the 2007-2009 recession resulted in an unprecedented increase in the potential duration of UI receipt. Beginning in late June, 2008, the maximum duration of UI benefits was extended multiple times, reaching 99 weeks for most UI-eligible job seekers as of late 2009. ${ }^{23}$ Congress has allowed the primary extension program to expire twice, most notably for nearly 2 months in June-July of 2010, but in each case renewed the extensions, which currently are effective through January 3, 2012.

In the context of the job matching function described earlier, increased availability of UI benefits is likely to increase unemployment duration through two primary behavioral channels. First, the extension of UI benefits, which represents an increase in their value, may reduce the intensity with which UI-eligible unemployed individuals search for work and their likelihood of accepting a given job offer. This could occur because the additional UI benefits reduce the net gains

\footnotetext{
${ }^{22}$ Such a reemployability rate is not unreasonable given the recent evidence on industry-mobility of workers (see Bjelland, Fallick, Haltiwanger, and McEntarfer, 2010)

${ }^{23}$ The joint Federal-State UI program provides up to 26 weeks of normal benefits. The recent benefit extensions reflect the impact of two federally funded programs: the permanently authorized Extended Benefits program, which provides up to 20 additional weeks of UI benefits, and the special Emergency Unemployment Compensation, which provides up to 53 weeks of benefits, depending on the unemployment rate in the recipient's state of prior employment (which causes the share of unemployed workers eligible for the 99-week maximum to change over time). The previous maximum eligibility was 65 weeks under the Federal Supplemental Benefits (FSB) program in the mid-1970s.
} 
from finding a job and also serve as an income cushion that helps households maintain acceptable consumption levels in the face of unemployment shocks (Chetty, 2008). Alternatively, the measured unemployment rate may be artificially inflated because some individuals who are not actively searching for work are identifying themselves as active searchers in order to receive UI benefits (a "reporting effect," in the language of Card, Chetty, and Weber, 2007). These behavioral effects on job search will increase the non-cyclical or structural component of the unemployment rate during the period over which extended benefits are available. ${ }^{24}$

Given the unique nature of recent economic conditions and the UI extensions, assessing the magnitude of the extended UI effect is challenging. Based on existing empirical research using U.S. data, Chetty (2008) noted that a $10 \%$ increase in the overall value of UI benefits increases unemployment durations by $4-8 \%$. Other estimates, particularly those that focus on extension periods rather than the dollar value of benefits, lie below this range (see for example, Card and Levine, 2000). As such, there is a wide range of uncertainty around the implied estimates of the impact of the recent UI extensions on unemployment duration. Moreover, as noted by others (e.g., Katz, 2010), the impact of UI benefits on job search likely was higher in the 1970s and 1980s than it is now, due to the earlier period's greater reliance on temporary layoffs and the corresponding sensitivity of recall dates to unemployment insurance benefits. As such, reliance on past estimates of the effects of UI generosity and duration on unemployment is likely to lead to overestimates of the effects of extended UI in the current economic environment. Hence, it is important to use recent labor market data to obtain estimates of extended UI effects.

Our own empirical assessment, reported in Daly, Hobijn, and Valletta (2011), ${ }^{25}$ focuses on direct calculation and comparison of the duration of unemployment for individuals who are eligible or not eligible for UI receipt, as reflected in their reported reason for unemployment. UI receipt generally is restricted to individuals who are unemployed through "no fault of their own," to quote U.S. Labor Department eligibility guidelines, and have recent employment history that allows them

\footnotetext{
${ }^{24}$ Our narrow focus on the direct behavioral effects of extended UI ignores the aggregate demand stimulus provided by UI payment, which reduces the cyclical component of the unemployment rate but does not affect the level of structural unemployment. Recent research suggests that multiplier effects of normal and extended UI payments are quite large (e.g., Vroman 2010), and the reduction in cyclical unemployment from this channel may exceed the increase in the structural component from the micro-behavioral channel.

${ }^{25}$ Based on the methodology introduced in Valletta and Kuang (2010a).
} 
to meet a base earnings test. In terms of the CPS, this means that UI eligible individuals are concentrated in the unemployed who classify themselves as "job losers."

Unemployment durations in 2009 and the first half of 2010 have increased by large amounts from their pre-recession baseline levels for both likely UI eligibles as well as ineligibles. However, the increase was larger for UI eligibles. If one fully attributes this difference to UI eligibility, then this points to an increase in the unemployment rate due to extended UI of about 0.8 percentage points. $^{26,27}$

The impact of extended UI on the unemployment rate is expected to dissipate as labor market conditions improve and the extended UI provisions are allowed to expire. As a result, extended UI does not affect the long-run JCC curve, though it might raise current reservation wages and thus suppress job creation in the short-run. ${ }^{28}$ As extended UI provisions expire the shifted Beveridge curve is expected move back inwards.

\subsection{Uncertainty}

In addition to mismatch and extended UI, overall uncertainty about economic conditions and policy is also considered a factor contributing to the outward shift in the BC and, more importantly, the low number of vacancies firms are posting.

The depth of the recession and the associated financial crisis increased the amount of uncertainty about the business environment within which firms operate. In case of fixed hiring and firing costs such uncertainty about the future state of aggregate demand lowers the option value of

${ }^{26}$ These results were relatively insensitive to alternative assumptions about the relationship between the stated reason for unemployment in the CPS data and likely eligibility for UI. Recent preliminary research that performs more elaborate analysis of monthly unemployment transitions, using matched CPS data and conditioning out the effects of individual characteristics and state economic conditions, finds even smaller impacts of extended UI, on the order of a 0.3 percentage point increase in the unemployment rate (Farber and Valletta 2011). However, this estimate is potentially plagued by measurement problems in the monthly CPS labor force transitions data and therefore is likely to represent a lower bound on the true effect of extended UI.

${ }^{27}$ Other recent estimates of the effect of extended UI on the natural rate of unemployment range from 0.7 percentage points (Aaronson, Mazumder, and Schecter 2010) to a maximum of 1.7 percentage points (Fujita, 2010).

${ }^{28}$ No quantitative analysis of this short-run effect exists. However, we expect this short-run effect of extended UI on the JCC to be small, since it is offset by the aggregate demand stimulus provided by UI payments. 
hiring new workers, thereby putting downward pressure on job creation (Bentolila and Bertola 1990, Bloom 2009).

Theoretical models of jobless recoveries, like Van Rens (2004) and Koenders and Rogerson (2005), suggest that firms might postpone hiring by temporarily boosting productivity growth. In Van Rens (2004), the boost of productivity growth comes from moving workers from the production of intangibles to the production of measured output. In Koenders and Rogerson (2005), firms choose to adopt organizational changes that improve productivity but were temporarily shelved during the prior expansion. In either case, the reorientation of production activity reduces the rate of hiring but raises productivity growth. This is what might have driven the significant deviation from Okun's Law in figure 6 during 2009 and 2010 (Daly and Hobijn, 2010).

Such temporary measures to boost productivity growth only go so far. If uncertainty remains elevated for a long time, the effect of these measures on productivity growth is likely to diminish and uncertainty mainly reduces job creation. This can possibly explain the joint low productivity growth and job creation in the first half of 2011.

Uncertainty might also contribute to the outward shift of the Beveridge curve, by causing firms that create vacancies at the same time they become more selective about filling them. Such a change in firms' hiring decisions would cause a decline in the number of hires per vacancy; it is also consistent with a reduction in recruiting intensity in the sense of Davis, Faberman, Haltiwanger (2010).

Though the high level of uncertainty is a possible explanation for the joint weakness in vacancy creation and vacancy yields we have observed relative to the strong productivity growth during the first part of the recovery, we would like to emphasize that there are no studies that have tried to quantify this effect. This is why, in Table 1, we list the effect of productivity growth on the Beveridge curve in parentheses, indicating ambiguity about its role. Since we expect a resolution of much of the uncertainty about economic situation throughout 2008 through 2011, we anticipate that the upward pressure of uncertainty on the natural rate of unemployment is temporary rather than permanent. 


\section{Conclusion}

The stubbornly high rate of unemployment in the face of ongoing GDP growth and rising job openings has raised concerns that the level of structural unemployment, or the natural rate of unemployment, has risen over the past few years in the United States. This is an important policy issue since short-run monetary and fiscal stabilization policies are not designed to alleviatestructural unemployment and can be costly if misapplied. ${ }^{29}$

In this paper we revisited a simple framework laid out in Pissarides (2001, Chapter 1) that is useful for understanding the movements of equilibrium unemployment. This framework models equilibrium unemployment as an outcome from the interaction of two curves - the Beveridge curve (BC) and the Job Creation curve (JCC) - and highlights the pitfalls of drawing conclusions about structural unemployment from movements in the $\mathrm{BC}$ alone. In addition, this framework supports our itemization and description of the factors that can change equilibrium unemployment on a transitory or more durable basis.

Using this framework we estimated the empirical BC and JCC and the implied values of equilibrium unemployment. The results suggest that the natural rate of unemployment has risen from its pre-recession level of 5.0 percent to a value between 5.4 and 6.4 percent, with our preferred estimate lying at the midpoint of 5.9 percent. This value implies an unemployment gap of over three percentage points, which remains quite high. Moreover, even at the top of the range of estimated natural rates, considerable slack remains in the labor market.

We then discuss the primary factors that have been identified as potential sources of an increase in the natural rate of unemployment over the past few years: mismatch between the characteristics of available jobs and workers, the extension of UI benefits, and recent uncertainty about economic conditions. Mismatch implies that the increase in equilibrium unemployment will partly persist, while the impacts of extended UI and uncertainty are likely to be transitory.

In terms of our estimated shifted Beveridge curve and long-run JCC, we only expect mismatch to have a long-run effect on the Beveridge curve and a negligible effect on the JCC. This

\footnotetext{
${ }^{29}$ In the case of monetary policy, expansionary policy when measured unemployment is near its natural rate can trigger inflation. In the case of short-run fiscal policy such as extended unemployment insurance, extensions for individuals who are mismatched may extend the period over which they make required adjustments in training or reservation wages.
} 
Daly, Hobijn, Şahin, and Valletta

comes with the observation, however, that there is very little research on the shape of the JCC. The main upside risk to our estimate of the natural rate is that there are factors that we did not identify that permanently drag down job creation going forward.

A better understanding of the determinants of job creation is not only crucial for the improving empirical analysis of equilibrium models of frictional unemployment. It is especially important for improving labor market policies. 


\section{References}

Aaronson, Daniel, Bhashkar Mazumder, and Shani Schechter (2010). "What is behind the rise in long-term unemployment?” Federal Reserve Bank of Chicago Economic Perspectives 2Q/2010: 28-51.

Abraham, Katherine G. (1987) "Help Wanted Advertising, Job Vacancies and Unemployment," Brookings Papers on Economic Activity, 207-243.

Abel, Andrew B., Ben S. Bernanke, and Dean Croushore (2011), Macroeconomics, $7^{\text {th }}$ edition, New York: Pearson.

Barnichon, Regis (2010), "Building a composite Help-Wanted Index,” Economics Letters, 109(3), 175-178.

Barnichon, Regis, Michael Elsby, Bart Hobijn and Ayșegül Șahin (2010) "Which Industries are Shifting the Beveridge Curve?" FRB SF Working Paper 2010-32.

Basu, Susanto, John G. Fernald, and Miles S. Kimball (2006) “Are Technology Improvements Contractionary?” American Economic Review, December 96(5), 1418-48.

Bentolila, Samuel, and Giuseppe Bertola (1990) "Firing Costs and Labour Demand: How Bad is Eurosclerosis?” Review of Economic Studies, 57, 381-402.

Bjelland, Melissa, Bruce Fallick, John C. Haltiwanger, and Erika McEntarfer (2010) "Employer-toEmployer Flows in the United States: Estimates Using Linked Employer-Employee Data,” Center for Economic Studies Working Paper 10-26.

Blanchard, Olivier, and Peter Diamond (1989) “The Beveridge Curve,” Brookings Papers on Economic Activity, 1-76.

Bloom, Nicholas (2009) “The Impact of Uncertainty Shocks,” Econometrica, 77, 623-685.

Bowden, Robert J. (1980) “On the Existence and Secular Stability of u-v Loci,” Economica, 47, 3350.

Brauer, David (2007) “The Natural Rate of Unemployment,” CBO Working Paper 2007-06.

Card, David, Raj Chetty, and Andrea Weber (2007) "The Spike at Benefit Exhaustion: Leaving the Unemployment System or Starting a New Job?.” American Economic Review Papers and Proceedings 97, 113-118.

Card, David, and Phillip B. Levine. (2000). "Extended benefits and the duration of UI spells: evidence from the New Jersey extended benefit program." Journal of Public Economics 78: 107-138.

Chetty, Raj. (2008). "Moral Hazard versus Liquidity and Optimal Unemployment Insurance." Journal of Political Economy 116(2, April): 173-234.

Congressional Budget Office (2011), The Budget and Economic Outlook: An Update, August 2011.

Daly, Mary C., and Bart Hobijn (2010) “Okun's Law and the Unemployment Surprise of 2009," FRB SF Economic Letter 2010-07. 
Daly, Mary C., Bart Hobijn, and Rob Valletta (2011) “The Recent Evolution of the Natural Rate of Unemployment," FRBSF Working Paper 2011-05.

Darby, Michael R., John C. Haltiwanger, and Mark W. Plant (1985) "Unemployment Rate Dynamics and Persistent Unemployment under Rational Expectations," American Economic Review, 75, 614-637.

Darby, Michael R., John C. Haltiwanger, and Mark W. Plant (1986) “The Ins and Outs of Unemployment: The Ins Win,” NBER Working Paper 1997.

Davis, Steven, Jason Faberman, and John Haltiwanger (2010) “The Establishment-Level Behavior of Vacancies and Hiring," NBER Working Paper No. 16265.

Diamond, Peter. 2011. "Unemployment, Vacancies, Wages." Lecture presented for the Sveriges Riksbank Prize in Economic Sciences in Memory of Alfred Nobel, Stockholm, Sweden. http://econ-www.mit.edu/files/6574

Elsby, Michael, Bart Hobijn and Ayșegül Șahin (2008) "Unemployment Dynamics in the OECD," NBER Working Paper 14617.

Elsby, Michael, Bart Hobijn and Ayșegül Șahin (2010) "The Labor Market in the Great Recession," Brookings Papers on Economic Activity, Spring 2010, 1-48.

Farber, Henry S., and Robert G. Valletta (2011), “Extended Unemployment Insurance and Unemployment Duration in The Great Recession: The U.S. Experience.” Mimeo, Federal Reserve Bank of San Francisco and Princeton University, June.

Fujita, Shigeru (2010). "Effects of the UI Benefit Extensions: Evidence from the Monthly CPS." Working Paper No. 10-35, Federal Reserve Bank of Philadelphia, November.

Fujita, Shigeru and Garey Ramey (2009) “The Cyclicality of Job Loss and Hiring,” International Economic Review, 50, 415-430.

Kaplan, Greg, and Sam Schulhofer-Wohl (2010) "Interstate Migration Has Fallen Less Than You Think: Consequences of Hot Deck Imputation in the Current Population Survey," FRB Minneapolis Working Paper 681.

Katz, Lawrence. (2010). "Long-Term Unemployment in the Great Recession." Testimony to the Joint Economic Committee, U.S. Congress. April 29, 2010.

Kocherlakota, Narayana (2010) "Inside the FOMC," Speech at Marquette, Michigan, August 17, 2010.

Koenders, Kathryn, and Richard Rogerson (2005), “Organizational Dynamics Over the Business Cycle: A View on Jobless Recoveries," Federal Reserve Bank of St. Louis Review, 87, 555579.

Kwok, Joyce, Mary C. Daly, and Bart Hobijn (2010) "Labor Force Participation and the Future Path of Unemployment,” FRB SF Economic Letter 2010-27.

Molloy, Raven, Christopher L. Smith, and Abigail Wozniak, "Internal Migration in the US: Updated Facts and Recent Trends," Federal Reserve Board of Governors, mimeo, 2010. 
Mortensen, Dale T. (1994) “The Cyclical Behavior of Job and Worker Flows," Journal of Economics Dynamics and Control, 18, 1121-1142.

Okun, Arthur M. (1962), "Potential GNP: Its Measurement and Significance," Proceedings of the Business and Economics Statistics Section of the American Statistical Association, 98-104.

Orphanides, Athanasios, and John C. Williams (2002) "Robust Monetary Policy Rules with Unknown Natural Rates,” Brookings Papers on Economic Activity, 2002-2, 63-118.

Petrongolo, Barbara, and Christopher A. Pissarides (2001) "Looking into the Black Box: A Survey of the Matching Function," Journal of Economic Literature, 39, 390-431.

Pissarides, Christopher A. (2000), Equilibrium Unemployment Theory, Cambridge, MA: MIT Press.

Pissarides, Christopher A. (2009) “The Unemployment Volatility Puzzle: Is Wage Stickiness the Answer?" Econometrica, 77, 1339-1369.

Reinhart, Carmen M., and Kenneth S. Rogoff (2009) "The Aftermath of Financial Crises," American Economic Review, 99, 466-472.

Şahin, Ayșegül, Joseph Song, Giorgio Topa, and Gianluca Violante, "Measuring Mismatch in the U.S. Labor Market," mimeo, 2011.

Schulhofer-Wohl, Sam (2010) "Negative Equity Does Not Reduce Homeowners' Mobility,” FRB Minneapolis Working Paper 682.

Shimer, Robert (2005) "The Cyclical Behavior of Equilibrium Unemployment and Vacancies," American Economic Review, 95, 25-49.

Shimer, Robert (2007), “Mismatch,” American Economic Review, 97, 1074-1101.

Sterk, Vincent (2010), “Home Equity, Mobility, and Macroeconomic Fluctuations,” DNB Working Paper No. 265.

Valletta, Robert G. (2010). "House Lock and Structural Unemployment.” FRBSF mimeo, November.

Valletta, Robert G., and Katherine Kuang (2010a). "Extended Unemployment and UI Benefits," FRB SF Economic Letter 2010-12.

Valletta, Robert G., and Katherine Kuang (2010b). "Is Structural Unemployment on the Rise?” FRB SF Economic Letter 2010-34.

Van Rens, Thijs (2004), “Organizational Capital and Employment Fluctuations,” CREI mimeo.

Vroman, Wayne (2010), "The Role of Unemployment Insurance As an Automatic Stabilizer During a Recession," Report, Urban Institute and IMPAQ International, July.

Wilson, Daniel J. (2010) “Is the Recent Productivity Boom Over?” FRB SF Economic Letter 201028. 
Daly, Hobijn, Şahin, and Valletta

Table 1. Factors that move the $\mathrm{BC}$ and JC curves.

\begin{tabular}{|c|c|c|c|}
\hline Shifter & JC & $B C$ & Transitory or Permanent \\
\hline \multicolumn{4}{|c|}{ Normal cyclical shifters } \\
\hline Shortfall in aggregate demand & $\sqrt{ }$ & & Transitory \\
\hline Elevated layoffs rate & $\sqrt{2}$ & $\Rightarrow$ & Transitory \\
\hline \multicolumn{4}{|c|}{ Other factors } \\
\hline Decrease in match efficiency (mismatch) & $\sqrt{ }$ & $\Rightarrow$ & Mostly transitory \\
\hline $\begin{array}{l}\text { Increased generosity of unemployment } \\
\text { insurance }\end{array}$ & $\sqrt{2}$ & $\Rightarrow$ & Transitory \\
\hline Uncertainty & $\sqrt{2}$ & $(\Rightarrow)$ & Transitory \\
\hline
\end{tabular}


Figure 1. Determinants of shifts in equilibrium unemployment.

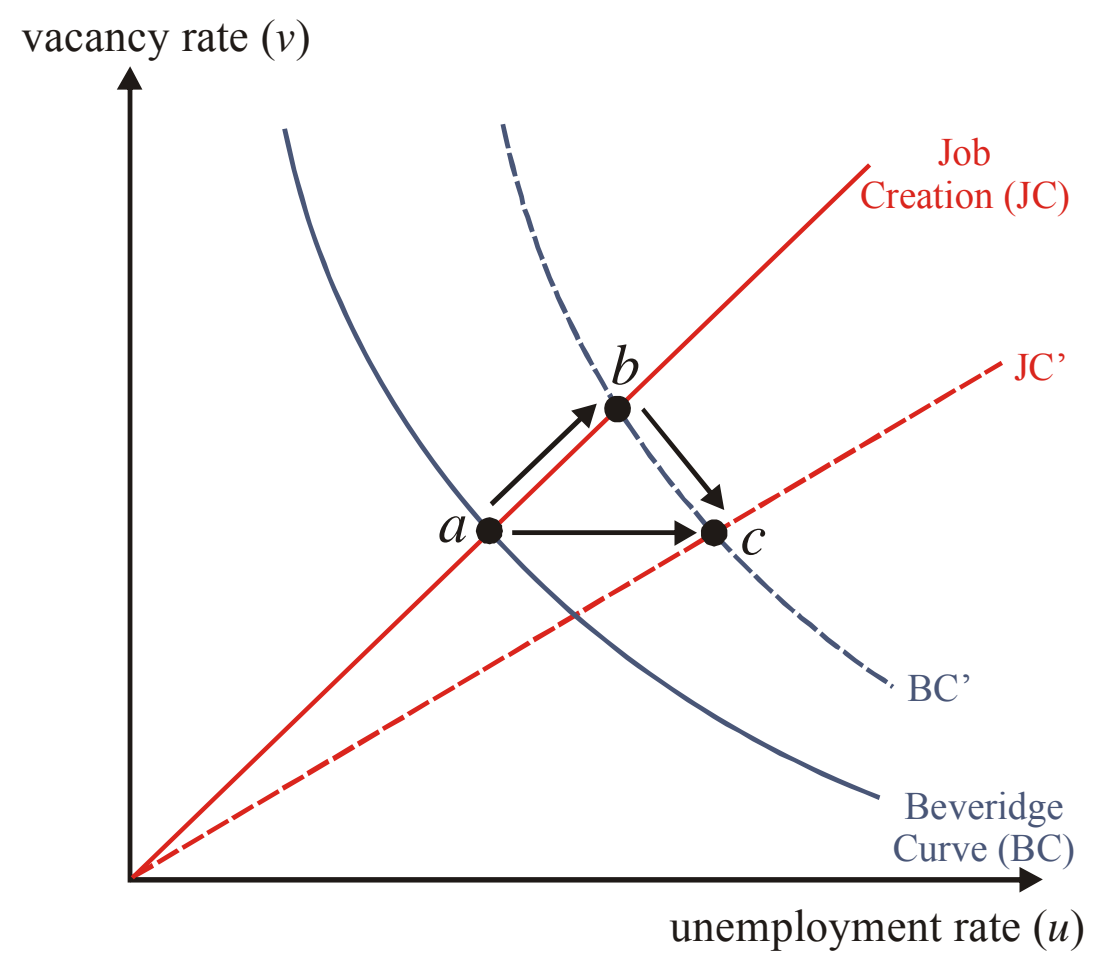

Figure 2. The U.S. Beveridge curve, December 2000-May 2011.

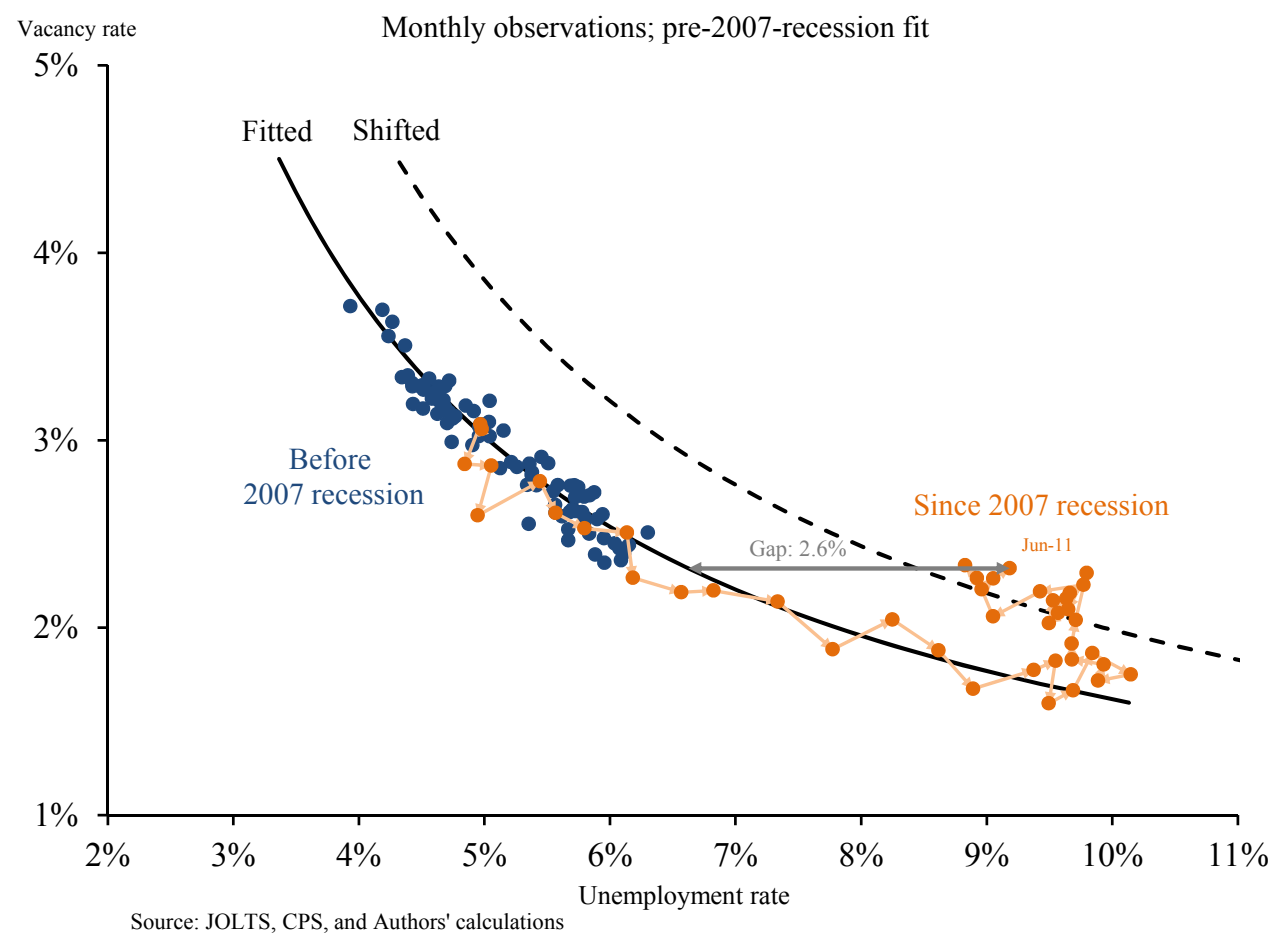


Figure 3. Historical shifts in the Beveridge curve.

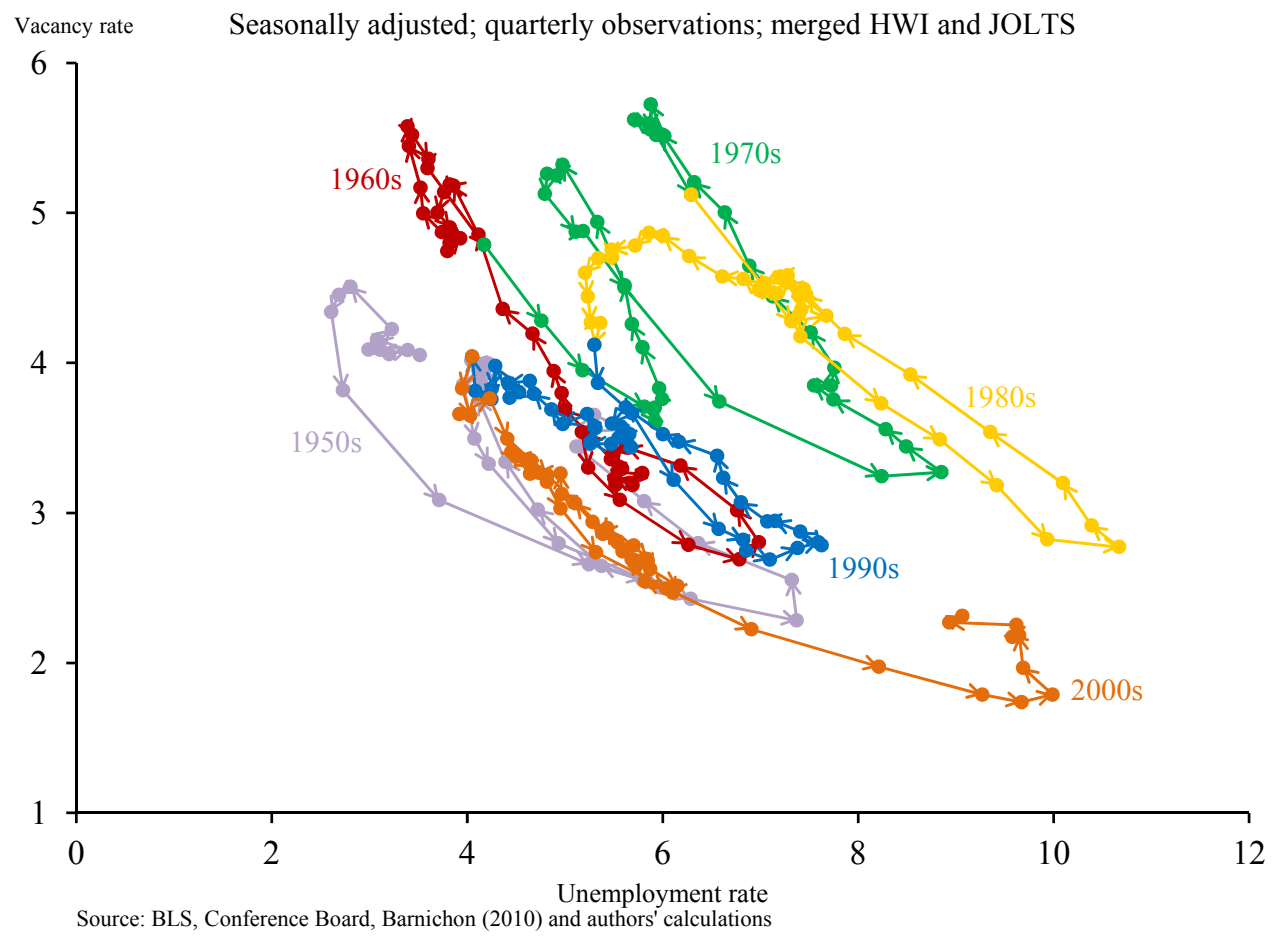

Figure 4. Estimated long-run Job Creation curve

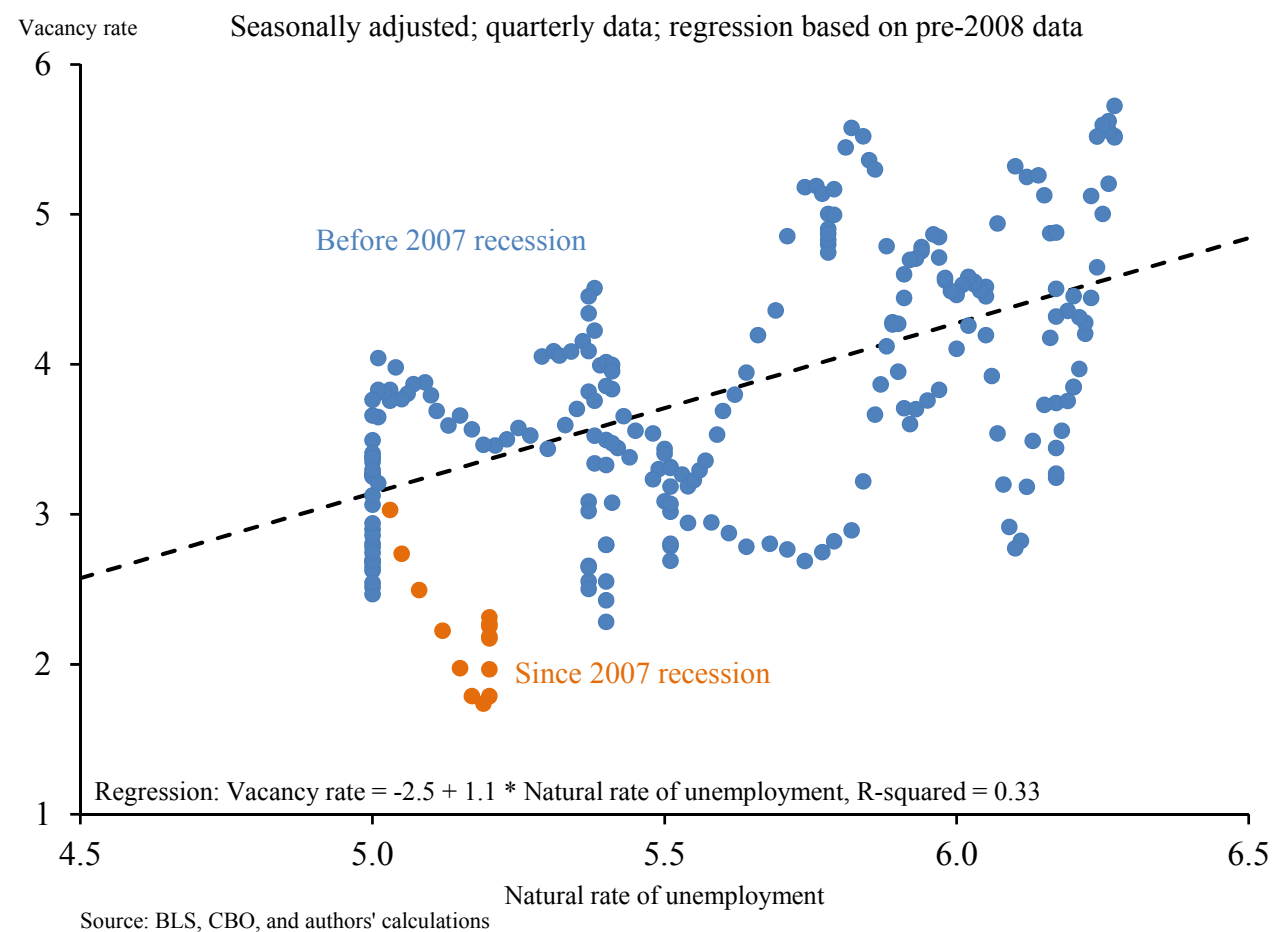


Figure 5. Estimated Job Creation and Beveridge curves

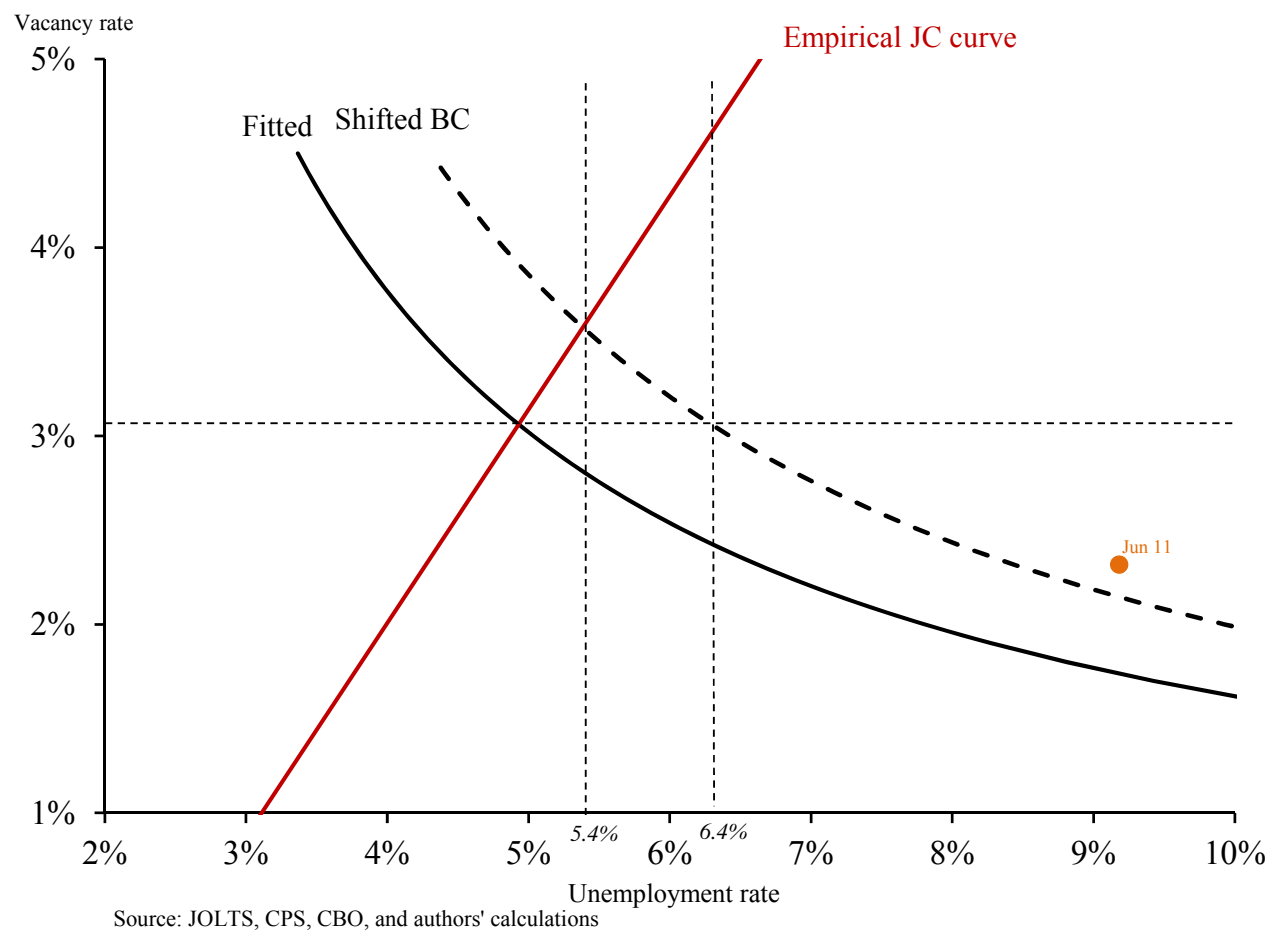

Figure 6. Okun's Law

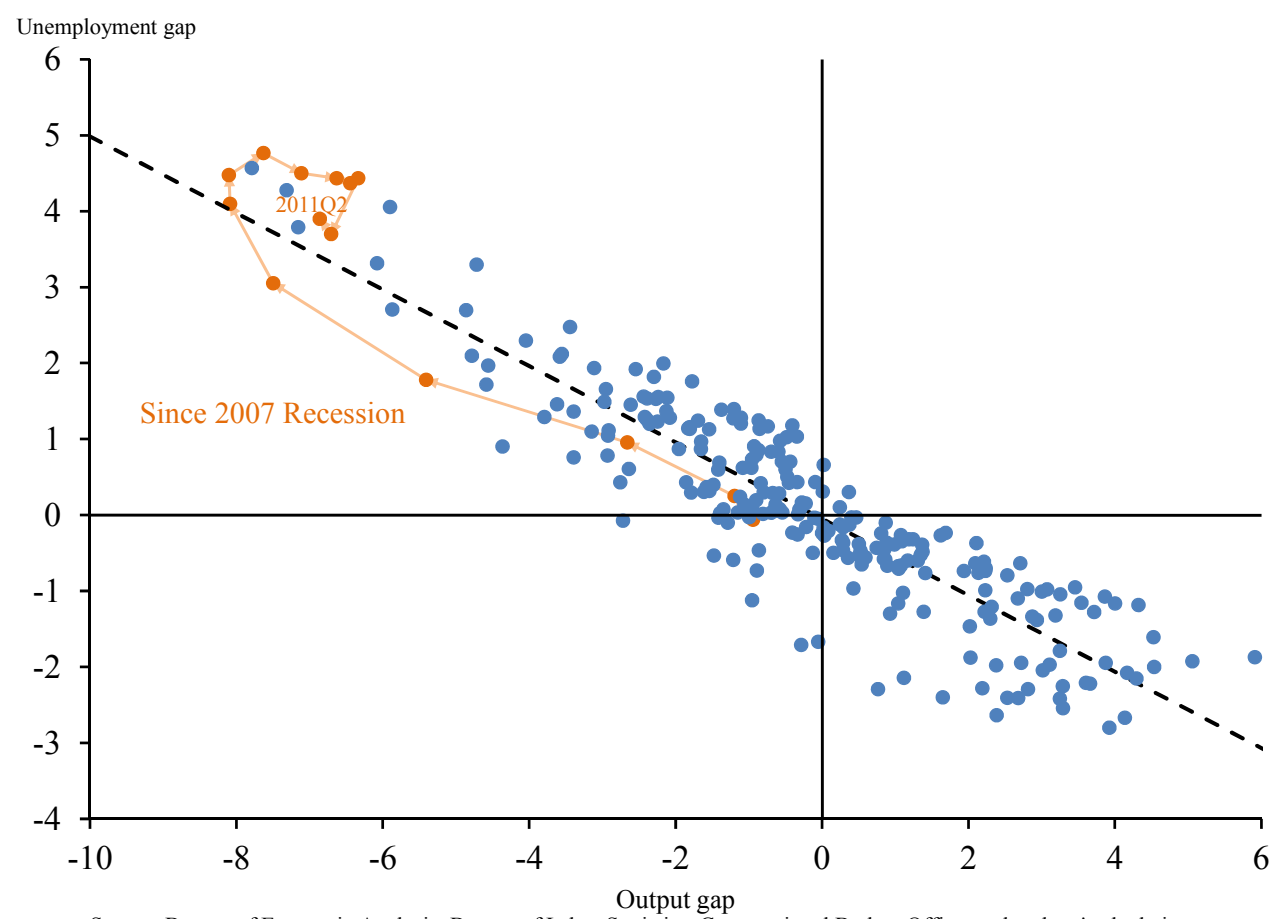

Source: Bureau of Economic Analysis, Bureau of Labor Statistics, Congressional Budget Office, and authors' calculations 